\title{
DA ESTÉTICA DO DESPORTO À ESTÉTICA DO FUTEBOL
}

\author{
MS. LUÍSA GAGLIARDINI GRAÇA \\ Mestre em Ciências do Desporto - Desporto para Crianças e Jovens, e Estudante de \\ Doutoramento em Ciências do Desporto pela Faculdade de Desporto \\ da Universidade do Porto (Portugal) \\ (Porto - Porto - Portugal) \\ e-mail: luisagagliardini@gmail.com
}

\begin{abstract}
DRA. TERESA OLIVEIRA LACERDA
Doutora em Ciências do Desporto e Professora Auxiliar da Faculdade de Desporto da Universidade do Porto (Portugal) e membro efectivo do CIFI2D (Centro de Investigação, Formação, Inovação e Intervenção em Desporto).

(Porto - Porto - Portugal)

e-mail: tlacerda@fade.up.pt
\end{abstract}

\begin{abstract}
RESUMO
O futebol é um facto social fruído por todas as pessoas, de todas as idades, profissões e credos, apresentando-se como um fenómeno de globalização que evidencia uma capacidade convocatória universal. O objetivo deste estudo consistiu em aprofundar o conhecimento acerca do futebol, com o contributo da abordagem estética, partindo para a exploração da sua importância na formação de jogadores. Para dar resposta aos objetivos, a metodologia percorrida baseou-se na síntese e confrontação de diversos estudos que desdobramos ao sabor das nossas próprias concepções, construindo um ensaio de natureza exploratória que, mais do que resumir conclusões includente e excludentemente delimitadas, pretendeu levantar questões que estimulem o estudo da temática.
\end{abstract}

PALAVRAS-CHAVE: Futebol; estética do desporto; estética do futebol; formação estética. 


\section{INTRODUÇÃO}

O futebol é um dos fatos sociais que mais exerce influências no estado de espírito e nas vivências emocionais diárias do mundo contemporâneo, sem sabermos, contudo, entendê-lo e explicá-lo completamente:

Quando me perguntam porque é que vou ao estádio, o que me atrai num desafio de futebol, confesso que fico extremamente embaraçado, não pela simplicidade da pergunta, pertinente e legítima, mas sobretudo pela complexidade e comprimento da resposta. Porque esta, sendo longa, não é resposta e, sendo curta também não o é, por ser redutora. Sinto-me à procura de algo que me foge por entre os dedos sem, no entanto, o saber definir concretamente. (BENTO, 2004, p. 63).

Esta temática apresenta-se, portanto, ao mesmo tempo perturbadora e atrativa, simplista e complexa, restrita e abrangente, singular e global.

O futebol possui uma natureza manifestamente estética, dinâmica, interativa e comunicativa que põe em evidência a permanente relação entre sujeito e objeto, sendo que o objecto, o jogo, é, ele mesmo, fruto da relação entre sujeitos que o constroem, e com ele e entre eles se envolvem. É o valor estético dessa construção que interpela, que comunica com o observador e com o atleta, sustentando e reforçando a experiência estética. Deste modo, o jogo alicerça-se na estética, já o afirmava Huizinga (1972) ao referir que o jogo tende a fazer-se acompanhar de toda uma série de elementos de beleza, reforçando que são múltiplos e muito íntimos os vínculos que o ligam à estética.

A reflexão sobre a experiência estética do homem em relação com o mundo que o rodeia, abre a possibilidade de se olhar para o interior da consciência humana e para o modo como esta experiência a realidade e lhe atribui significação.

Ainda que, tendencialmente, as questões estéticas se associem exclusivamente ao âmbito da sensibilidade, importa clarificar como é que o ser humano é capaz de sentir, enquanto ser completo e uno.

De acordo com estudos recentes no âmbito das neurociências (DAMÁSIO, 1999, 2000) a antiga crença no hipotético dualismo entre sentimentos e razão começa a perder sentido, na medida em que as suas fronteiras se apresentam cada vez mais ténues. Não se trata de negar a diferenciação da razão e da emoção e sua importância, mas de salientar que tão prejudicial pode ser a sua amálgama como o seu isolamento na vida e no conhecimento do homem, na relação consigo próprio e com o mundo. Segundo Damásio (1999), a redução das emoções pode constituir uma fonte igualmente importante de comportamentos irracionais, tanto como a redução da razão. Para este autor, a dependência da razão (razão superior) relativamente 
às emoções e sentimentos (cérebro "inferior"), ao contrário de a transformar em razão inferior, engrandece-a de capacidades e potencialidades, conferindo-lhe guias cognitivos internos e eficazes meios de comunicação de significados a terceiros. Deste modo, "os nossos mais refinados pensamentos e as nossas melhores ações, as nossas maiores alegrias e as nossas mais profundas mágoas, usam o corpo como instrumento de aferição." (DAMÁSIO, 1999, p.18), tornando a emoção parte integrante dos processos de raciocínio e tomada de decisão, para o pior e para o melhor (DAMÁSIO, 2000). Neste sentido e, de acordo com Gladwell (2005), a avaliação estética da realidade possibilita a sua melhor compreensão e descodificação, conferindo mais objetividade à sua avaliação se, pela experiência, realçarmos os seus efeitos positivos e reduzirmos o seu potencial negativo, o que implica que, pelo menos, não a ignoremos. Com efeito, o cérebro humano e o resto do corpo constituem uma totalidade indissociável, interagindo com o exterior em unidade, experimentando assim uma relação estética com o mundo que os envolve. Essa relação, simultaneamente emocional e racional, é educável e persegue a formação e aquisição de competências de interação com o mundo, que decorrem não da soma, mas da conciliação entre sentimentos e cognição.

Convém sublinhar que à racionalidade da biologia, da biomecânica, do treino desportivo, que tantos avanços têm proporcionado ao desenvolvimento do desporto contemporâneo, não é estranha a paixão e a sensibilidade com que os investigadores orientam os seus trabalhos. No confronto com os dilemas surgidos no decurso da pesquisa científica, são os próprios investigadores a declarar, não raras vezes, que o prosseguimento nesta ou naquela direção se fundou numa certa intuição, num sentimento algo inexplicável do ponto de vista puramente racional. Por seu lado, o escultor, o escritor ou o fotógrafo, que encontram no desporto fonte de inspiração e de expressão, beneficiam do conhecimento esclarecido do tema que representam. Também os estudiosos da estética do desporto, pese embora o fato de o seu contributo subjetivo enriquecer o esclarecimento do objecto de estudo, orientam a sua produção académica pelo rigor e pelo método requeridos à racionalidade científica.

Estas considerações preliminares assumem relevância num estudo que visa compreender a experiência estética do homem em confronto com o desporto, particularmente com o futebol, onde o corpo se constitui um teatro ilimitado de emoções, intenções e ações que possibilitam ao ser humano descodificá-lo, conhecê-lo e transcender-se no Homo Sportivus, referido por Bento (2007), que num esforço máximo de divinização visa atingir a sua máxima humanização. É o corpo desportivo deste Homo Sportivus que o mesmo autor (BENTO, 1995) considera como um artefato da cultura desportiva e que convoca a estética para a sua autorrealização, para a edificação 
da identidade, para a realização do eu. Neste sentido, a experiência desportiva está entretecida na dimensão estética, permitindo ao ser humano interagir, comunicar, conhecer, criar, reconstruir, reinventar e redescobrir-se (LACERDA, 2002b).

É na consciência daquilo que de mais essencial existe na natureza do futebol, que emerge a pertinência e a necessidade do seu estudo a partir da abordagem estética. Este trabalho parte de uma perspectiva geral acerca da estética do desporto e do pressuposto de que a experiência estética promove um conhecimento mais aprofundado do desporto (no caso vertente, do futebol). Procura refletir-se, de modo interpretativo e compreensivo, sobre a natureza estética do jogo e sobre a necessidade de a formação em futebol não negligenciar a dimensão estética.

\section{DA ESTÉTICA DO DESPORTO À ESTÉTICA DO FUTEBOL}

O estudo da estética do futebol encontra necessariamente os seus fundamentos e origens no seio da já algo abrangente abordagem estética do desporto.

Para Gumbrecht (200I), o ponto de partida para a aproximação estética ao desporto baseia-se na indiscutível competência dos verdadeiros fãs para ajuizar se um jogo foi bonito ou feio - independentemente do resultado final, fato que evidencia a inevitável relação estética entre o homem e o desporto. Esta relação é também, de algum modo, inconsciente na medida em que, geralmente, nos deparamos com uma enorme dificuldade em fundamentar em que conceitos ou critérios nos baseamos para desenvolver tais apreciações.

O interesse em estudar as diversas atividades desportivas sob o olhar estético é manifestamente crescente (BEST, 1988), já que transportar para o universo desportivo uma linguagem comummente atribuída, de forma quase exclusiva, à arte, permite enriquecer a compreensão e apreciação de aspectos essenciais à natureza do desporto, para os quais a linguagem estética (e não necessariamente artística) possui enorme aplicabilidade (ROBERTS, 1995). Também Huizinga (1972) nos conduz a questionar e a pôr a descoberto os múltiplos e estreitos vínculos entre o desporto e a estética, ao afirmar categoricamente que a beleza do corpo humano em movimento encontra a sua máxima expressão no jogo.

A compreensão da natureza do desporto implica que o "levemos a sério" enquanto fenómeno estético, como propõe Gumbrecht (200 I ), reconhecendo-o como um privilegiado local social do prazer do belo. Não se trata apenas, portanto, de olhar para o fenómeno desportivo a partir de uma perspectiva outra, mas sobretudo de entrarmos na sua essência e de assumirmos que na hierarquia de valores associados ao desporto, os valores estéticos não podem ser negligenciados 
na pirâmide axiológica, pelo risco de lhe suprimir uma das suas dimensões matriciais (LACERDA, 2002a).

Deste modo, a análise do desporto a partir do ponto de vista estético não se apresenta tarefa fácil, não só porque requer uma atitude interrogativa, fora da polarização do preto e do branco (BENTO, 1995), mas também porque exige do homem a audácia de olhar para dentro de si e contemplar a sua complexidade. Por este motivo, e como sublinha Grumbrecht (200 I), o reconhecimento da natureza estética do desporto parece ser uma constatação fácil e pacífica por parte de qualquer apreciador, apesar da identificação concreta das suas causas e manifestações, dos seus conceitos, critérios e categorias, do seu sentido e relações, aparentarem ser de mais difícil descodificação, porque a sua experienciação não é (e porventura não se pretende que seja) minimamente imparcial ou distanciada: "Não por acaso se diz que os clubes são do coração, o topos corporal no qual se representam as emoções, e os distintivos dos clubes estão fixados do lado esquerdo do peito." (DAMO, 200 I , p. 85). Contudo, uma apreciação estética do desporto não se esgota na identificação das subjetivas questões de gosto ou de clubismos, remetendo antes para o reconhecimento e compreensão do seu valor estético, o que reclama a identificação de categorias estéticas, mais ou menos subjectivas, que lhe são subjacentes.

Para Damo (200 I ), o entendimento da natureza estética do fenómeno desportivo requer a identificação das categorias que o tornam tão denso e envolvente, justificando o autor que grande parte do interesse pelo espectáculo desportivo se deve à expectativa relativamente ao seu desfecho, portanto, à sua imprevisibilidade, fazendo referência ao risco e à excitação como categorias estéticas que lhe são permanentemente associadas.

A estética do desporto manifesta-se concretamente, segundo Osterhoudt ( $|99|$ ), na procura de padrões de excelência, na intimidade entre a audiência e o performer, na intensidade, espontaneidade, e jogabilidade, aspectos aos quais Lacerda $(2004,2007)$ acrescenta a interação entre colaboradores e opositores, a luta por vencer as dificuldades colocadas pelo adversário, as estratégias de parceria e cumplicidade com os companheiros, a experiência de superação das limitações próprias e das adversidades do jogo, o domínio técnico evidenciado pelos jogadores, as decisões e opções tácticas que conduzem à concretização das jogadas, a eficácia, a economia dos gestos e o permanente ambiente comunicativo. Também Masterson ( 1983 ) identifica os movimentos individuais e de grupo, ataque e defesa, contraataque, ritmo, cor, composição, elegância, estilo, graça, poder e economia, como categorias evidenciadoras do potencial estético desportivo, às quais Boxill (1988) adita as categorias competição e vitória, transcendência e superação, cooperação e competição, desafio e excelência. 
Perante a diversidade de atributos emergentes da abordagem estética do desporto, torna-se pertinente (ainda que muito mais complexo) procurar o seu sentido, em busca de manifestações concretas e específicas de uma estética do futebol.

No entendimento de Kupfer (1988a, 1988b), o futebol apresenta um elevado potencial estético que se manifesta na confrontação e cooperação, na permanente adaptação e readaptação aos constrangimentos do jogo que proporciona uma infinidade surpreendente de movimentos, ritmos e situações. De acordo com Huizinga ( 1972) o conceito de ordem possui também uma profunda afinidade, absoluta e peculiar, com o jogo, conferindo-lhe atributos estéticos.

É possível, assim, reconhecer particularidades que, de alguma forma, nos despertam para a natureza estética do futebol, porque de fato sabemos e sentimos que ele anima em nós algo que por vezes nem reconhecemos ter: a capacidade de fruição e relação com o belo, convocando-nos, e convocando uma enormidade de pessoas que dele deseja fruir, refletindo, no dizer de Prado (1997), como que uma contiguidade emocional à escala mundial.

Mas como atribuir sentido e significado a todos estes atributos? Como descodificá-los, entendê-los, organizá-los e contextualizá-los? Urge, então, problematizar e argumentar quanto ao modo como a apreciação estética é necessária ao conhecimento do futebol, enfatizando como tal apreciação pode ficar inviabilizada, ou pelo menos comprometida, sem um conhecimento mais aprofundado do que de essencialmente estético há no jogo.

\section{A COMPREENSÃO DA NATUREZA ESTÉTICA DO JOGO DE FUTEBOL}

Quero acentuar premonitoriamente (assim muito à vista de toda a gente, como é meu hábito) que sou um frequentador assíduo das bancadas dos grandes estádios e que me embriago com esse capricho imprevisível, esse esquivo imponderável, que é o acto criador do artista-jogador-de-futebol (SÉRGIO, 2003, p. I79).

O futebol é um jogo envolvente que, por enformar permanentemente os gostos e os interesses do seu público, os seus parâmetros éticos e estéticos, individuais e coletivos, possui uma capacidade convocatória indiscutível (DAMO, 200 I). Não é possível, contudo, ignorar, que tal identificação e relação é contextualizada pelos valores e paradigmas da sociedade em geral, que funcionam como "lente" perante a qual qualquer indivíduo observa e experiência o futebol (NERI MARINHO, 2007). Deste modo, a relação autêntica do indivíduo com os fatos sociais com que se depara pode ficar comprometida, e até diluída, perdendo-se na multidão anónima que o despersonaliza (ORTEGA e GASSET, 1993), no seio de inúmeros 
interesses sociais, políticos, e até "clubísticos" que de algum modo influenciam a experiência estética.

Além disso, segundo Constantino (2007), o desporto é um meio de expressão e afirmação de identidades sociais e culturais, o que caracteriza e molda permanentemente os estilos de jogar futebol, fato observável na sobrevalorização técnica dos latinos, na exaltação individual dos sul-americanos, na sobreposição da força dos alemães e no sentido colectivo do jogo dos ingleses (LOBO, 2002).

Contudo, independentemente dos atributos percepcionados, e admitindo que qualquer "futebol" pode incluir técnica, valores individuais, força e sentido coletivo de jogo, o que nos impede de questionar e procurar o que de essencial existe neste jogo, considerando-o como um primum com qualidades próprias que desencadeiam respostas estéticas no homem? No estudo da estética do futebol encontramo-nos perante um objeto com um carácter subjectivo peculiar, na medida em que ele é, em grande escala, partilhado, invocando sensibilidades manifestamente colectivas com repercussões globais (GAGLIARDINI GRAÇA, 2008).

Damo (200 I), defende que a popularidade do futebol se deve, em grande medida, a um aspecto central da sua natureza: o fato de ser praticado com os pés e, por isso, exigir do homem um comportamento de algum modo antinatura (utilizando os pés não apenas para a locomoção mas, em simultâneo, para uma enorme diversidade de habilidades para as quais não aparentam estar vocacionados), cujo sucesso ou fracasso será mais facilmente associado a apreciações de ordem mágica e a componentes contingenciais, como a sorte ou o infortúnio, e nem sempre à eficácia ou falta dela, o que possibilita que cada gesto, cada momento, sejam acompanhados de maior expectativa e incerteza. Este nível de imprevisibilidade evoca também uma necessidade de adaptação e readaptação aos constrangimentos circunstanciais do jogo que lhes dê resposta, aspectos referidos por Kupfer (1988a, 1988b) e Lacerda (2004, 2007), e supracitados na argumentação inicial deste trabalho, como categorias indispensáveis à apreciação estética do desporto.

Para além da reflexão sobre as particularidades do modo de jogar futebol, é também importante a consideração do seu sentido, da sua finalidade, o que conduz ao binário processo e produto e remete para uma visão mais global do jogo.

"As leis da ciência moderna são um tipo de causa formal que privilegia o como funciona das coisas em detrimento de qual o agente ou qual o fim das coisas." (SOUSA SANTOS, 1987, p. 16). Estudos centrados nas qualidades do objeto desportivo categorizam os diferentes desportos em aesthetic sports (modalidades estéticas), em que a componente estética do processo constitui o produto desejado; e, em purposive sports (modalidades propositivas), em que a finalidade se caracteriza por um produto quantitativo concreto (BEST, 1988). 
A compreensão do valor estético não só do processo, mas também do produto desportivo, sobretudo considerado enquanto consequência natural do processo, torna-se indispensável no seio de uma abordagem estética do futebol, enquanto purposive sport. Contudo, e como evidencia Weber (1979), é fundamental partir de abordagens mais compreensivas do que explicativas, procurando o entendimento do sentido das ações dos indivíduos e não apenas o aspecto exterior dessas mesmas ações: "Parte da estética desportiva não está ao alcance de quem observa apenas a forma. Desse ponto de vista, o futebol mais parece uma sequência de lances inócuos, repetitivos e sem sentido." (DAMO, 200 I , p. 86). Deste modo, a beleza no futebol não pode ser considerada de um modo redutor enquanto forma exterior, enquanto aparência a perseguir a qualquer custo, mas através da expressão de atos belos e bons, executados para realizar uma certa finalidade repleta de sentido e significado, escapando ao risco de permanecer no mero «esteticismo» que afluiria no efémero, sem inspiração ou convocação universal e inevitavelmente individualista. Se assim fosse, suprimir-se-iam categorias estéticas do desporto já identificadas como relevantes para o seu carácter comunicativo, tais como a intimidade (OSTERHOUDT, 199|), a interação, parceria e cumplicidade (LACERDA, 2004, 2007), e a cooperação (BOXILL, 1988), desembocando forçosamente na incomunicabilidade.

Partindo deste enquadramento e considerando a apreciação estética do jogo de futebol, verifica-se que dos jogadores e das equipas não se esperam apenas gestos tecnicamente bem executados, cuja beleza possa ser contemplada em si mesma, espera-se sobretudo que esses gestos e comportamentos configurem uma relação de poder (categoria estética do desporto também reconhecida por Masterson, 1983), de vantagem, isto é, de eficácia, em função da finalidade e do sentido do próprio jogo (DAMO, 200 I).

Qual será então, a relação entre o jogar bem e o jogar bonito?

A transcendentalidade atribuída ao belo e ao bem na filosofia clássica, sugere uma intercambialidade entre estas categorias e a noção de ser. Deste modo, tudo o que é (existe), é sempre algo de bom e de belo, assim como tudo o que é bom, é, bem como tudo o que é belo, é (isto é, existe). A partir deste entendimento, pode considerar-se então uma relação de interdependência entre o jogar bonito e o jogar bem, sendo que jogar bem é bonito e o jogar bonito é bem, conduzindo-nos para a bondade e eficácia do belo, bem como, para a beleza do bem e do seu sentido/finalidade.

No entanto, a reciprocidade entre os valores estéticos e éticos parece ter desaparecido até à posmodernidade, sendo mesmo considerados, na atualidade, totalmente independentes e isolados, surgindo, no dizer de Max Weber ( 1986) um politeísmo dos valores e uma segregação entre o belo e o bem. 
Descortinemos, então, a aplicabilidade de tais conceitos ao futebol, procurando relações entre os seus valores estéticos (que integram, mas extrapolam a noção de belo) e os seus valores éticos, considerando estes últimos como valores que caracterizam e vão de encontro à sua natureza, finalidade e sentido. Apenas clarificando estas noções aplicadas ao jogo de futebol tal tarefa se torna possível, já que, como evidencia Lobo Antunes (2008), todos os substantivos e adjectivos abstratos são perigosos e manipuláveis.

Esta contextualização requer, evidentemente, uma procura de conhecimento do jogo, do seu conteúdo e natureza. Se, segundo Frade (2007), a expressão estética manifestada pelas ações tático-técnicas no jogo requer uma elevada cultura de jogo, essencialmente táctica, poderemos pensar que a sua leitura e apreciação também, tendo em vista uma adequação ao objeto estético que vai para além da forma. É, aliás, por este motivo que, para o autor, a estética do futebol não é normalmente detectável por quem não se identifica com a essência do fenómeno e, com frequência, se deixa influenciar pelo acessório, também integrante da dimensão estética, mas que se constitui como que um prolongamento, fazendo, por preconceito, opor o jogar bonito ao jogar bem e à eficácia.

Neste contexto, a vitória (por exemplo), objetivo central do jogo, não se opõe à liberdade de experiência estética nem do observador, nem do atleta, mas o melhor resultado potencia expoentes estéticos mais elevados (KUPFER, 1988a; BOXILL, 1988). Também Damo (200 I) defende que o resultado não só é importante para entender o juízo dos adeptos, mas principalmente para entender a própria lógica do jogo de futebol, no qual o produto influencia de tal modo a sensibilidade de todos os intervenientes, que acaba por se tornar uma categoria determinante. Para o autor o desfecho possível do gol pode proporcionar aos espectadores o prazer estético pela forma de uma execução primorosa, proporcionando, contudo, o mesmo êxtase pela expectativa criada e, sobretudo, pela sua importância para o resultado final.

Kupfer (1988a) reconhece que o produto, a quantificação, desempenham um papel de elevada importância nos jogos desportivos coletivos, mas tais facetas não subsistem isoladas, estando subordinadas e adaptadas ao jogo, ao processo, cujo desenvolvimento não está pré-determinado, enfatizando o papel da improvisação, da imprevisibilidade, da incerteza, da criatividade, da invenção e da inovação, frente a frente com o adversário. Deste modo, a estética do desporto não se manifesta apenas no propósito externo de ganhar, mas é internamente definida pelo modo de jogar necessário a esse desfecho, como manifestação de excelência. Em convergência, e a partir do pensamento de Sumanik e Stoll (1989) relativamente ao desporto em geral, é possível inferir que, no futebol, o valor estético do jogo 
prende-se com a criação e construção (processo) singular e ímpar do seu fim desejado: a vitória (produto).

"Esse é o ritmo próprio do futebol: muitas ameaças, poucos gols." (PRADO, 1997, p. 213). A relação entre o gol e os processos de construção do "jogar" em futebol, isto é, entre processo e produto, assume-se como um dos aspectos centrais não só para a consideração estética do fenómeno, mas sobretudo para a compreensão da sua natureza, na medida em que lhe confere sentido e significado. Verifica-se convergência com este ponto de vista em Roberts (1995) que sustenta que o produto da atividade desportiva deve ser entendido como uma consequência natural de um processo que a esse fim conduziu. Assim, o gesto "inútil" assume um valor estético definhado relativamente ao gesto portador de sentido e significado. Destarte, o gol inicia-se muito antes de a bola entrar na baliza e esse momento não pode ser distinguido de todos os elementos que, direta ou indiretamente, contribuem para a sua totalidade. Deste modo, tudo o que se passa longe da bola, e antes do gol, deve ser considerado enquanto manifestação da finalidade/intencionalidade da equipa como um todo, tanto como aquilo que se passa perto da bola, e no momento do gol. Por conseguinte e, de acordo com Frade (2007), quando absolutizamos um qualquer adorno estético de um gesto, independentemente da sua finalidade e efeitos, mutilamos o seu valor, porque a estética do jogo é exaltada quando reflete a natureza do fenómeno.

Em suma, a natureza essencial do jogo de futebol possui, como condição indispensável, a aliança entre a estética e o rendimento, sendo que, no dizer de Moderno ( 1 998), o seu hipotético antagonismo constitui um falso conflito e, quanto mais o jogo for jogado com "arte", melhor servirá à competição. Há, portanto, no futebol, uma relação de causalidade entre processo e produto que deve ser considerada esteticamente:

A extensão do aspecto estético dá-se no compromisso da eficácia em direcção à vitória do atleta ou do grupo. A esteticidade não deve se sobrepor aos interesses da vitória, mas simplesmente ser uma colaboradora indispensável justamente em função da busca competente da vitória. Um alto rendimento desportivo é um bom e belo desempenho, regra geral". (MODERNO, 2004, p. 4).

O valor emotivo que o sucesso comporta (DAMÁSIO, 2004), confere também maior atração estética ao jogo no que à eficácia, isto é, ao produto, diz respeito. É neste sentido que Boxill ( 1988) salienta o desejo de vitória como componente fulcral à dimensão estética do desporto (podendo nós concretizá-lo para o futebol), referindo que um jogo bem jogado só ocorre quando envolve o desejo de ganhar (promovendo a concentração e performances superiores), sendo agradável 
do ponto de vista estético. Então, a beleza é um dos elementos constituintes da vitória e, simultaneamente, um modo de a expressar, porque a eficácia e o sucesso podem ser belos.

Todo o esforço por aprofundar o conhecimento sobre o complexo conteúdo do futebol assume grande relevância quando pensamos em formação e ensino do jogo. Esse conhecimento é a base para a construção de um processo que conduza com fidelidade à aprendizagem do jogo, proporcionando aos jogadores a aquisição de ferramentas capacitadoras da sua experienciação genuína, livre e eficaz. O reconhecimento da natureza estética do jogo de futebol, convoca para a importância da uma formação estética no processo de formação desportiva, conduzindo, de acordo com Barros Marques e Fróis (1999) à formação global do indivíduo e ao desenvolvimento das suas potencialidades cognitivas.

\section{FORMAÇÃO EM FUTEBOL E FORMAÇÃO ESTÉTICA}

Num ensaio sobre a formação estética em futebol é relevante não só procurar clarificar o que caracteriza a experiência estética no confronto com o futebol, mas sobretudo procurar descortinar a sua importância pedagógica. Para Noronha Feio ( 1975) a educação da sensibilidade passa pela experiência e consciência do fazer, bem, com graça, ritmo, eficiência, que ao extrapolar a mera realização mecanicista, conduz-nos a fontes perpétuas de prazer e educação.

Consideramos o encontro estético como um elemento chave no processo formativo em futebol. Tal abordagem possibilita um enfoque na singularidade que é promovida pela educação estética e que estimula para o reconhecimento, para a recriação, procurando que os indivíduos aprendam novos modos de ver, de pensar e de compreender o mundo, pelo estímulo dos órgãos de percepção, bem como da sensibilidade interior e pelo desenvolvimento do sentido crítico (LACERDA, 2009).

Não só a experiência estética engrandece as possibilidades de compreensão do desporto, sendo que a observação (suscitadora de um espectro alargado de interações e experiências de prazer) se reveste de elevado valor pedagógico (LACERDA, 2004), como também "A fantasia, a imaginação, a empatia, desenvolvidas pelo processo de observação do Desporto, fomentam a comunicação de cada um com o seu íntimo, favorecem um melhor sentimento de si, alargam e redimensionam a singularidade de cada um". (LACERDA, 2004, p. 7).

Contudo, a pessoa esteticamente instruída, não é apenas aquela com capacidade de falar de certos objetos ou situações, de descrevê-los ou comentá-los, mas sim quem possui uma capacidade para neles experimentar, compreender e participar (COLLINSON, 1973, apud ARNOLD, 1988) - não se constitui, assim, o processo 
de formação dos jovens jogadores de futebol num momento privilegiado para formar e desenvolver a literacia estética? Para Sérgio (2003), a dimensão estética é fundamental na formação global dos jovens jogadores, sendo os seus efeitos o resultado de um envolvimento pessoal e afetivo nas ações e comportamentos, reflexo da personalidade e expressão da emotividade de uma ação perfeita, que pode ser vivida e contemplada. No entanto, e de acordo com Andrieu ( 1980), o prazer estético assume expoentes superiores na realização relativamente à observação, sendo que esse prazer resultante da realização implica um envolvimento livre e criativo, que conduz ao aperfeiçoamento e promove o desejo de superação dos modelos. Assim, a exaltação estética inerente à facilidade de realização do movimento resulta do autoconhecimento, da mestria do julgamento, do controle das emoções, do amor e sensibilidade com que se vive essa experiência, sendo o efeito estético um elemento fulcral para a procura do autoaperfeiçoamento e para a alegria da experiência de fruição do corpo. Tal fruição é enaltecida quando o encontro entre conhecidos (sujeito e objeto) é, como afirma Neri Marinho (2007, p. 19) "[...] consumado por territórios de sedução, territórios íntimos, de convite ao toque, territórios conhecidos e plenos de sentido", proporcionadores de experiências de prazer. A experiência do prazer é, também para Noronha Feio (1978), uma componente indispensável à formação pelo desporto. É ainda no prazer que se inscreve a afirmação de Duchamp (1990, p. 60): "Era sempre a ideia de divertimento que me levava a fazer as coisas e a repeti-las três vezes [...]".

Deste modo, assinalamos a indispensabilidade de uma experiência estética prazenteira, já que, como afirma Damásio (2004), estados de alegria e de felicidade permitem modos mais eficientes de pensar, uma maior fluência de ideias e uma maior facilidade de atuar, por possibilitarem ao organismo o alcance de um maior estado de perfeição, conduzindo a uma maior propensão para o sucesso. Neste sentido, e de acordo com Maciel (2008), o estado de supramotivação proporcionado pela experiência de prazer na prática do futebol, revela-se determinante para o sucesso das aprendizagens efetuadas e para a expressão de desempenhos de excelência.

Compreender a relevância da experiência estética enquanto elemento pedagógico fundamental apresenta-se como um passo evidente na construção de um processo formativo coerente em futebol. Como salienta Andrieu ( 1980 ) ainda que haja algo do belo percepcionado de forma sensorial, a sua apreensão e reconhecimento requerem a intervenção de uma certa compreensão e educação que se enriquecem pela experiência. Torna-se assim indispensável explorar qual deverá ser a natureza ou o conteúdo dessa experiência, para que ela possa, verdadeiramente, estimular respostas estéticas sensíveis à essência do jogo. 
Educar consiste em dar um mundo a alguém que não o tem, «imundando-o» através da possibilidade de construção do seu próprio mundo (SANTOS, 1982). De acordo com Damásio (1999, 2000), a riqueza da experiência na aprendizagem reside no fato de, em contato com o ambiente, o ser humano fazer muito mais do que interagir e gerar respostas externas espontâneas ou reativas, produzindo também respostas internas. Pela constituição de imagens internas (visuais, auditivas, tácteis, viscerais, somatossensoriais), o homem procede à sua organização, estabelecendo assim a base para o pensamento e para a compreensão, por meio de uma aquisição de experiência factual e emocional com o ambiente. Esta argumentação focaliza-nos no carácter educável do ver, ouvir e interpretar que Lacerda (2004) sobreleva e que pela experiência, conduz à aprendizagem.

De acordo com este entendimento, será então indispensável considerar a importância de proporcionar, na formação em futebol, a «imundação» do futebol, na qual se inscreve a «imundação» da bola, rumo ao ser jogador, sendo-o. É ao jogador que importa chegar, pelos seus próprios meios, à sua realização, através da qual se conhece, se experimenta e se vence (SÉRGIO, 2003).

A «imundação» do futebol possibilita que, como refere Damo (200 I), os atletas, a partir do domínio de certas técnicas elementares pelo treino, sejam capazes de improvisar, de criar durante um espetáculo de futebol, fazendo com que cada jogo seja único.

Contudo, é fundamental a consciência de que formar exige tempo, o que numa época da "instantaneidade" como a que vivemos (GLEICK, 2003), se torna quase inacessível. Além disso, formar exige esforço dos intervenientes, o que numa sociedade marcada pelo culto do desejo, e da sua satisfação imediata (LIPOVETSKY, 1989), perde significado e reconhecimento. Não obstante, formar exige também o desfrutar do mundo para o qual despertamos, o que muitas vezes pode ficar comprometido com a ansiedade e a pressa. Neste sentido, o futebol, à imagem da sociedade, parece constituir-se como mais um mundo de impaciência, o que, segundo Valdano (1998), não apresenta quaisquer virtudes pedagógicas.

Para Jones (2006), a infância tem vindo a ser progressivamente encurtada, e a chegada à fase adulta é cada vez mais precoce, restando pouco tempo para brincar e para viver o ser criança resultando, segundo Gleick (2003), numa redução do desenvolvimento do espírito criativo e da espontaneidade, (bem como da diversidade), características indispensáveis a um espaço de criação estética no futebol.

Sobrinho Simões, em entrevista concedida a Maciel (2008), sublinha que uma das consequências negativas da globalização é a homogeneização das crianças, por exemplo, através da comunicação social e das brincadeiras cada vez mais pré-formatadas a que são submetidas. Maciel (2008) acrescenta que grande parte 
da homogeneização que se observa no futebol, resulta da formatação indevida das atividades de treino proporcionadas aos jovens. Também a este propósito Massada, em entrevista concedida a Maciel (2008), refere que a homogeneização do jogo de futebol, como consequência da mecanização do treino, é menos visível em determinados contextos culturais, como é o caso do Brasil, onde as brincadeiras de rua, repletas de diversidade, ainda estão presentes, e onde a criatividade e a individualidade são dimensões culturalmente valorizadas. Descortinamos também aqui uma das principais características do jogo, enunciada por Huizinga (1972): a liberdade. Também Bento (20 I0), reforça que a noção de liberdade no desporto constitui uma ponte fundamental à expressão estética do corpo e dos sentidos. É, então, fundamental a consciência de que a quantidade e diversidade de experiências vividas em contexto desportivo contribuem para a estruturação e formação do eu de cada um, educando no sentido da descoberta de respostas livres mais favoráveis e adequadas em diferentes contextos, respostas essas que o próprio jogador terá de desenvolver e criar.

Valdano (2008) chama a atenção para o fato de, com frequência, os processos de formação penalizarem o jogador distinto e criativo em benefício do obediente, que toda a vida joga mediante um "ditado", não sabendo o que fazer com a liberdade, atributo que consideramos de extrema relevância no seio de um enquadramento estético do futebol. A este respeito, Lacerda (2009) assinala a importância de uma formação estética altamente personalizante para a construção da identidade de cada um, o que apenas se torna possível se, sob o conselho de Manuel Sérgio (2003), fizermos do contexto de formação desportiva um "tempo para a liberdade".

\section{CONSIDERAÇÕES FINAIS}

Ainda que, como procuramos evidenciar neste ensaio, a estética do jogo seja algo intrínseco à sua natureza e que, portanto, dele emerge naturalmente, é fundamental a compreensão de que o seu desenvolvimento não se dá por mero acaso no seio de qualquer processo de ensino-aprendizagem do futebol. Ela resulta da construção de processos que contemplam e compreendem o futebol enquanto realidade estética, não descurando esta sua dimensão pela sobre-enfatização fragmentada de aspectos técnicos, físicos, psicológicos ou táticos.

Enquanto fenómeno estético, caracterizado pela diversificação, a paixão pelo futebol, que se adquire desde muito cedo, parece ter vindo a desaparecer no seio de uma lógica "involutiva" que o tem vindo a contaminar em fases de experiência cada vez mais precoces, onde a diversificação é cada vez menor e, como ninguém tem necessidade daquilo que desconhece, e a criação e recriação nos conduz para além do conhecido, o desenvolvimento estético e criativo dos jogadores fica comprometido 
(FRADE, 2007). Este desenvolvimento consiste em descobrir soluções que à primeira vista não existem, aceitar qualquer circunstância de jogo, recusando-se a bloquear as ações (GLADWELL, 2005), remetendo para uma estética do inesperado, construtora de respostas de eleição e superiores à nossa expectativa. Deste modo é possível manter a "jogabilidade" (OSTERHOUDT, 199I) que é atraente porque, por meio de desempenhos reveladores da "excelência" (BOXILL, 1988 e OSTERHOUDT, 199I), é “imprevisível” e "infindável” (KUPFER, 1988a, I988b).

\section{From the aesthetics of sport to the aesthetics of football}

ABSTRACT: Football is a social fact enjoyed by everyone, of every age, professions, beliefs, presenting itself as a globalization phenomenon that shows a particular capacity of universal gathering. The aim of this study was to deepen the knowledge of football, with the contribution of the aesthetics approach going on to the exploration of its importance on the players' education. In order to respond to these objectives, the methodology used was based on the summary and confrontation of several studies that we unfold using our own conceptions, writing an exploratory essay that, more than resuming including and excluding delimited conclusions, allows us to bring up questions that stimulate inquiry about of theme.

KEYWORDS: Football; aesthetics of sport; aesthetic of football; aesthetic education.

\section{De la estética del deporte hasta la estética del fútbol}

RESUMEN: El fútbol es un hecho social disfrutado por todas las personas, de todas edades, profesiones y creencias presentándose como un fenómeno de globalización que refleja una particular capacidad de llamamiento universal. El objetivo de este estudio consistió en profundizar el conocimiento sobre el fútbol con la aportación del enfoque estético, partiendo hacia la exploración de su importancia en la formación de jugadores. Intentando dar una respuesta a los objetivos, la metodología recorrida se basó en la síntesis y confrontación de diversos estudios que vamos desplegando al correr de nuestras propias concepciones, construyendo un ensayo de naturaleza exploratoria que, más que resumir conclusiones incluyente y excluyentemente delimitadas, busca levantar cuestiones que estimulen el estudio de la temática en causa.

PALABRAS CLAVE: Fútbol; estética de lo deporte; estética del fútbol; formación estética.

\section{REFERÊNCIAS}

ANDRIEU, G. L'effet esthétique en éducation physique ou étude historique de quelques concepts. Travaux \& Recherches en E. P. S., INSEP, n. 6, p. 160-170, 1980.

ARNOLD, P. J. Education, movement and the curriculum. New York: The Falmer Press, 1988. 
BARROS MARQUES, E.; FRÓIS, J. P. Conclusões da conferência: Educação estética e artística. NOESIS. Instituto de Inovação Educacional. DOSSIER. n. 52, p. 3, 1999.

BENTO, J. O. O outro lado do Desporto. Porto: Campo das letras - Editores, S. A., 1995. O. Desporto. Discurso e substância. Porto: Campo das letras - Editores, S.

A., 2004.

Do "Homo Sportivus": relações entre natureza, cultura e técnica. Revista Brasileira de Educação Física e Esporte, S. Paulo, v. 7, n. 4, p. 31 5-330, 2007.

Da Coragem, do Orgulho, da Paixão de ser Professor. Autorretrato. 2. ed. Belo Horizonte: Casa da Educação Física. 2010.

BEST, D. The aesthetic in sport. In: MORGAN, W. J. \& MEIER, K. V. (eds.). Philosophic inquiry in sport. Champaign, Illinois: Human Kinetics Publishers, Inc., I 988. p. 477-493.

BOXILL, J. M. Beauty, sport and gender. In: MORGAN, W. J. \& MEIER, K. V. (eds.). Philosophic inquiry in sport, Champaign, Illinois: Human Kinetics Publishers, Inc, 1988. p. 509-5I 8.

CONSTANTINO, J. M. (2007). Os valores educativos do desporto - Representações e Realidades. In: BENTO, J. \& O. CONSTANTINO, J. M. (eds.). Em Defesa do Desporto- Mutações e Valores em Conflito, Coimbra: Almedina Edições, SA., 2007. p. 57 - 79.

DAMÁSIO, A. O erro de Descartes: Emoção, razão e cérebro humano. Mem Martins: Publicações Europa - América, Lda, 1999.

O sentimento de si. O corpo, a emoção, e a neurobiologia da consciência.

Mem Martins: Publicações Europa - América, Lda. 2000.

Ao encontro de Espinosa: As emoções sociais e a neurologia do sentir. Mem Martins: Publicações Europa - América, Lda. 2004.

DAMO, A. Futebol e Estética. S. Paulo em perspectiva, S. Paulo, v. I5, n. 3. p. 88-91. 2001 .

DUCHAMP, M. Engenheiro do tempo perdido. Lisboa: Assírio e Alvim. 1990.

FRADE, V. Entrevista realizada por Neri Marinho, D. sobre o entendimento existente acerca da Estética do Futebol. Documento não publicado. 2007.

GAGLIARDINI GRAÇA, M. L. Novos desafios para a Formação do Futebol Contemporâneo: que Formação Estética no Jogo?. 2008. 288 f. Dissertação (Licenciatura) - Curso de Educação Física e Desporto, FADEUP, Porto, 2008.

GLADWELL, M. Blink. Lisboa: Publicações Dom Quixote, 2005.

GLEICK J. Cada Vez Mais Rápido. Lisboa: Temas e Debates, 2003.

GUMBRECHT, H. U. A forma da violência: em louvor da beleza atlética. Folha de S. Paulo, S. Paulo, p. 6-9. 2001 . 
HUIZINGA, J. Homo ludens. Madrid: Alianza Editorial, S. A, 1972

JONES, S. A Descendência do Homem. Lisboa: Gradiva, 2006.

KUPFER, J. Sport - The body electric. In: MORGAN, W. J.; MEIER, K. V. (eds.). Philosophic inquiry in sport. Champaign, Illinois: Human Kinetics Publishers, Inc., I988a. p. 455-475.

KUPFER, J. A commentary on Jan Boxill's "Beauty, sport and gender". In: MORGAN, W. J.; MEIER, K. V. (eds.). Philosophic inquiry in sport. Champaign, Illinois: Human Kinetics Publishers, Inc., 1988b, p. 519-522.

LACERDA, T. O. Elementos para a construção de uma Estética do Desporto. 2002. 322 f. Dissertação (Doutoramento), Ciências do Desporto, Departamento de Estética do Desporto, Faculdade de Ciências do Desporto e Educação Física, Porto, 2002a.

A estética como uma dimensão de referência para o desporto do século XXI. Horizonte, Lisboa, v. I8, n. 104, p. 18-20, 2002b.

Acerca da natureza da experiência estética desencadeada pelo encontro com o desporto e do seu contributo para a educação estética do ser humano. In: LEBRE, E.; BENTO, J. O. (Eds). Professor de Educação Física. Ofícios da Profissão. Porto: Edição FCDEFUP, 2004. p. 301-307.

A Magia dos Jogos Desportivos e a Estética do Desporto. In: ACTAS DO ${ }^{\circ}$ CONGRESSO INTERNACIONAL DE JOGOS DESPORTIVOS. [CDROM]. Porto, 2007.

LACERDA, T. O.; GONÇALVES, E. Educação estética, dança e desporto na escola. Revista Portuguesa de Ciências do Desporto, Porto, v. 9, n. I, p. I05-I |4, 2009.

LIPOVETSKY, G. A era do Vazio. Lisboa: Relógio de Água, 1989.

LOBO, L. F. Os Magos do Futebol. Lisboa: Bertrand Editora, 2002.

LOBO ANTUNES, A. Escrevo pela mesma razão que a pereira dá peras. Revista LER, Lisboa, p. 33-43, maio 2008.

MACIEL, J. A(In)(Corpo)r(Acção) Precoce dum jogar de Qualidade como Necessidade (ECO) ANTROPOSOCIALTOTAL - Futebol um Fenómeno AntropoSocialTotal, que "primeiro se estranha e depois se entranha» e ... logo, logo, ganha-se!. 2008. 680 f. Dissertação (Licenciatura) - Curso de Educação Física e Desporto, FADEUP, Porto: 2008.

MASTERSON, D. Sport, theatre and art in performance. In: LENK, H. (ed.). Tropical problems of sport philosophy. Schorndorf: Verlag Karl Hofmann, 1983. p. 169-I83.

MODERNO, J. R. Estética do futebol. PRAXIS da Educação Física e dos Desportos, Brasília, v. I, n. 2), p. 5I-60. 1998.

. Filosofia da criação desportiva: extensão e limites estéticos, éticos e tecnológicos da cultura desportiva. Sessão: inovação, tecnologia e cultura. In: X CONGRESSO DE CIÊNCIAS DO DESPORTO E EDUCAÇÃO FÍSICA NOS PAÍSES DE LÍNGUA PORTUGUESA, 2004, FCDEF - Porto. 
NERI MARINHO, D. Valor estético do Futebol: o olhar do apreciador com conhecimento profundo do jogo. 2007. 127 f. Dissertação (Licenciatura) - Curso de Educação Física e Desporto, FADEUP, Porto: 2007.

NORONHA FEIO, J. Educação Física e Desporto: Porto. Edições, ASA. 1978.

NORONHA FEIO, J. Desporto e Política: Lisboa. Portugália, Editora. 1975.

ORTEGA Y GASSET, J. La rebelion de las masas. Madrid: Aliança Editorial. 1993.

OSTERHOUDT, R. The philosophy of sport: an ovenview. Champaign, Illinois: Stipes Publishing Company, 1991.

PRADO, D. de A. Seres, coisas, lugares: do teatro ao futebol. São Paulo: Cia. das Letras, 1997.

ROBERTS, T. Sport, art, and particularity: the Best equivocation. In: MORGAN, W. J.; MEIER, K. V. (eds.). Philosophic inquiry in sport. Champaign, Illinois: Human Kinetics Publishers, Inc., 1995. p. 495-507.

SANTOS, D. Obras Completas: Da Filosofia - Do Homem. Lisboa: Fundação Calouste Gulbenkian, v. 2, 1982.

SÉRGIO, A. Para uma nova dimensão do Desporto. Colecção Epistemologia e Sociedade. Lisboa: Divisão Editorial Instituto Piaget, 2003.

SOUSA SANTOS, B. Um discurso sobre as ciências. Porto: Edições Afrontamento, 1987.

SUMANIK, I.; STOLL, S. A philosophic model to discuss the relationship of sport to art. Sport Science Review, Champaign, n. 12, p. 20-25, 1989.

VALDANO, J. Los Cuadernos de Valdano. Madrid: El Pais Aguilar, 1998.

VALDANO, J. No princípio era a bola. A Bola. Lisboa, I l out. 2008.

WEBER, M. Sobre a Teoria das Ciências Sociais. Lisboa: Presença, 1979.

WEBER, M. Le savant et le politique. Paris: Plon, 1986.

Recebido: 08 jan. 2010 Aprovado: 13 jan. 2011

Endereço para correspondência: Luísa Gagliardini Graça, Teresa Oliveira Lacerda Faculdade de Desporto da Universidade do Porto Rua Dr. Plácido Costa, 9I - 4200.450 Porto. PORTUGAL 